\title{
A IMAGINAÇÃO SOCIOLÓGICA E A PRODUÇÃO DE SABERES EM COMUNIDADES RURAIS DA REGIÃO DE CATALÃO-GO
}

\author{
Maria Zenaide Alves ${ }^{*}$ \\ Wender Faleiro*
}

RESUMO: Este texto tem por objetivo desenvolver algumas reflexões a partir de uma atividade de formação, desenvolvida na disciplina Sociologia e Educação do Campo durante o tempo comunidade, com discentes do curso de Licenciatura em Educação do Campo da UFG, Catalão - GO. O intento foi provocar nos discentes o exercício da imaginação sociológica buscando estimular a apropriação e reelaboração dos conhecimentos; suscitar reflexões sobre a importância da sociologia para o trabalho docente; estimular a pesquisa e a busca pelo conhecimento local para a construção de novas pedagogias voltadas à realidade do campo. As reflexões apresentadas advêm de diálogos entre alguns autores estudados na disciplina, docente, e sujeitos entrevistados, cujas vozes se apresentam mediadas pelos discentes que conduziram os trabalhos de campo. Conclui-se que os discentes refletiram e compreenderam a importância de se buscar o diálogo com as pessoas mais velhas, de conhecer o mundo que os cerca, também a partir do olhar dessas pessoas, e não apenas dos livros. Compreenderam os movimentos sociais do campo a lutarem por reforma agrária e por uma educação libertadora.

Palavras-chave: Educação do Campo; Sociologia; Memórias da escola.

\begin{abstract}
This paper aims to develop some reflections from a training activity, developed in Sociology and Field Education discipline during the time community, with students of the Education in the Field of UFG, Catalão-GO. The intent was to provoke students pursue the sociological imagination seeking to stimulate the appropriation and re-elaboration of knowledge; raise reflections about the importance of sociology for teaching; stimulate research and the search for local knowledge to the construction of new pedagogies focused on field reality. The reflections presented come from dialogues between some authors studied in the discipline, teacher and interviewees, whose voices are presented mediated by students who conducted the fieldwork. It concludes that the students reflected and understood the importance of seeking dialogue with older people, to know the world around them, also through the eyes of these
\end{abstract}

\footnotetext{
Núcleo de Extensão e Pesquisa em Educação e Desenvolvimento do Campo (NEPCampo). Docente da Faculdade de Educação - Universidade Federal de Goiás (UFG) - Regional Catalão (Campus I). Doutora em Educação pela Universidade Federal de Minas Gerais (UFMG). E-mail: zenpiaui@yahoo.com.br

* Núcleo de Extensão e Pesquisa em Educação e Desenvolvimento do Campo (NEPCampo). Docente do Programa de Pós-Graduação em Educação - Universidade Federal de Goiás (UFG) - Regional Catalão (Campus I). Doutor em Educação pela Universidade Federal de Uberlândia (UFU). E-mail: wender.faleiro@gmail.com
} 
people, and not only from books. They understood the field social movements to fight for land reform and a liberating education.

Keywords: Field Education; Sociology; School memories.

\section{INTRODUÇÃO}

“... Os grandes produtores que deram estudos aos seus filhos e estes com conhecimento puderam transformar suas terras. Nasceram ricos e puderam estudar. Sabe de uma coisa? Nem daqui eles são. Vieram do Sul e arrendaram as terras de quem realmente não conseguia plantar. Eu mesmo fui um deles que arrendei para a minha sobrevivência." (Sr. Divino. Idade não informada.)

O Sr. Divino não estudou além do suficiente para aprender assinar o nome. Seus filhos, provavelmente, também não foram muito além. Seus netos possivelmente frequentam a escola. Os netos do Sr. Divino estão chegando às escolas e universidades, e veem desafiando o sistema educacional brasileiro nos últimos anos. Eles são os "outros sujeitos" de quem fala Miguel Arroyo (2012) e têm, conseguintemente, demando dos educadores e gestores outras pedagogias (também nos termos de Arroyo).

A chegada desses "outros sujeitos" dentro do sistema escolar nos impõe como principal desafio saber quem são; que histórias levam para dentro da escola; onde e como vivem; que saberes trazem consigo; o que demandam da escola e, com isso, que pedagogias dariam conta de responder às suas demandas. Pedagogias, assim, no plural, porque esses "novos sujeitos" também são plurais. Mesmo as populações rurais, de quem trataremos nesse texto, precisam ser vistos e tratados na sua diversidade, afinal, não possível falar no campo brasileiro, no singular.

Para responder a tais desafios, novas estratégias metodológicas são exigidas do fazer docente uma vez que esses sujeitos, por serem historicamente excluídos do sistema escolar e da produção do conhecimento, inexistem nas pedagogias. Assim, para estabelecer o diálogo e incluí-los no 
sistema educacional, eles têm sido chamados a escreverem suas próprias histórias e construírem, junto com as escolas e universidades, pedagogias que respondam às suas demandas e expectativas.

Foi com esse propósito que a disciplina Sociologia e Educação do Campo, do curso de Licenciatura em Educação do Campus da Universidade Federal de Goiás-Regional Catalão desenvolveu algumas das suas atividades. Nesse sentido, este escrito é fruto de um trabalho desenvolvido no Tempo Comunidade, que consistia em estabelecer diálogos entre os saberes acadêmicos e os saberes comunitários, buscando produzir conhecimento com e sobre as comunidades rurais onde vivem e trabalham os estudantes. Cada dupla ou trio de discentes deveria entrevistar um adulto ou idoso da sua comunidade buscando trazer ao debate os conhecimentos dos entrevistados sobre as questões sociológicas discutidas na disciplina. O intento foi provocar nos discentes o exercício da imaginação sociológica, conceito cunhado pelo sociólogo norte-americano Charles Wright Mills para definir a capacidade de pensar sociologicamente abstraindo-nos das nossas experiências individuais e olhando os fatos com um olhar mais elaborado, para o qual a sociologia deve contribuir. De acordo com Giddens (2003), “a imaginação sociológica permitenos ver que muitos dos fenômenos, que parecem dizer respeito apenas ao indivíduo, na verdade refletem questões mais amplas" (p. 3). Nesse sentido, o conceito foi apresentado no início da disciplina, buscando estimular a apropriação e reelaboração dos conhecimentos estudados ao longo do semestre. Acreditamos que isso provocaria nos discentes reflexões sobre a importância da sociologia para o trabalho docente, bem como estimularia a pesquisa e a construção de conhecimento sociológico na perspectiva local, visando a produção de saberes e a construção de novas pedagogias voltadas à realidade do campo nesse contexto.

Assim, as reflexões aqui apresentadas são frutos de um diálogo entre alguns autores estudados na disciplina, intermediados pela docente, e os sujeitos entrevistados, ${ }^{1}$ cujas vozes se apresentam mediadas pelos discentes

\footnotetext{
${ }_{1}$ A amostra foi integrada pela totalidade de sujeitos, que aceitaram, esclarecidos e livres em participar da pesquisa. Os nomes dos mesmos foram preservados, com o uso de pseudônimo.
} 
que conduziram os trabalhos de campo e abordam especificamente questões educacionais. Os referencias teórico-metodológicos que orientam este artigo são, por um lado, autores que compõem a bibliografia básica do programa da disciplina e, por outro, um grupo de 12 moradores de municípios rurais da microrregião de Catalão, com idade variando entre 51 e 85 anos de idade.

Para contextualizar a análise buscamos, inicialmente, trabalhar alguns aspectos do território explorado. Uma característica desta microrregião que tem relação direta com as questões discutidas no curso, nesta e em outras disciplinas, é a presença de minérios, extraídos por empresas como Anglo American, Fagundes e Vale. Aqui são exploradas jazidas de brita, fosfato, nióbio², titânio, vermiculita, urânio, tório, estrôncio (FERREIRA, 2012). Estes depósitos são alvo de extrações exploradas por empresas multinacionais, ou serão, haja vista que as empresas habitualmente têm comprado propriedades para extrações futuras. Prática recorrente no município, conforme já exemplificado, e denunciado por moradores em Audiências Públicas realizadas nos últimos dez anos (2003-2013) para discutir as questões ambientais da região, é a compra do subsolo, executada, inicialmente sem o desalojamento das famílias, que terão que fazê-lo no momento da extração, sem data préestabelecida. Estas empresas chegaram a região na década de 1970, o que promoveu um aumento da população urbana de 129,83\% decorrente da migração de pessoas de outras cidades para Catalão. No meio rural ocorreu o oposto, um decréscimo de $22,74 \%$ atribuído ao deslocamento de camponeses para a cidade em busca de empregos para acesso a uma renda (MENDONÇA, 2004).

O curso de Licenciatura em Educação para o Campo foi implantado na UFG Regional Catalão a partir do resultado do edital de seleção № 2/2012 SESU/SETEC/SECADI/MEC de 31 de agosto de 2012, divulgado na Portaria $n$. 72, de 21 de dezembro de 2012 da SECADI e publicado no DOU edição n. 249, de 27 de dezembro de 2012. O objetivo é formar professores habilitados ao magistério no Ensino Fundamental e Médio com habilitação em Ciências da Natureza.

2 A Anglo América é uma das três maiores produtoras de nióbio do mundo (fonte: http://www.angloamerican.com.br/our-operations/niobio.aspx?sc_lang=pt-PT) 


\section{REFERENCIAIS TEÓRICOS}

Partimos da premissa que hoje não é mais possível falar em rural, no singular, mas em ruralidades. Neste sentido, acreditamos que é necessário conhecermos esse rural do qual falamos e de onde se originam nossos estudantes e entendermos quem são esses sujeitos: assentados? Acampados? Agricultores familiares? Trabalhadores do agronegócio? Pequenos proprietários rurais? Donas de casa? Ativistas e militantes de movimentos sociais do campo? Enfim, se estamos falando de ruralidades, também estamos de falando de povos do campo, de culturas do campo, de modos de produção diferenciadas no campo, por isso acreditamos na importância de conhecer esse contexto porque somente assim podemos desenvolver práticas educativas efetivas e pensar metodologias que dialogam com as especificidades dos nossos alunos. Nessa perspectiva, nosso entendimento da categoria rural não se limita à oposição ao urbano, até porque tratar o rural em oposição ao urbano e tomá-lo na singularidade pode mascarar dicotomias dentro do próprio território rural. Ou seja, não há um rural, um campo, o que existem são campos, são ruralidades, haja vista que o rural do agronegócio não é o mesmo do agricultor familiar; o rural das secas não é o mesmo rural das águas; o rural dos homens não é o mesmo rural das mulheres; o rural da infância não é o mesmo rural dos jovens e dos adultos, etc.

Isso nos remete a outra premissa que é o fato de que o rural não pode ser resumido ao agrícola, como aprendemos historicamente. Essa é uma abordagem crítica da questão, segundo Carneiro (1998, p. 57) que se opõe à visão dualista que opunha o "rural" ao "urbano" como duas realidades empiricamente distintas e normalmente definidas uma em negação da outra, com base em critérios meramente descritivos, informados pelo paradigma que associa o "rural" ao agrícola e ao "atrasado" e o "urbano" ao industrial e ao "moderno".

O rural contém o agrícola, mas os territórios rurais são mais do que lugares de produção econômica, são territórios de vida, de cultura, de produção de saberes, como defende Martins (2002, p. 225) para quem "as populações 
rurais são mais que instrumentos de produção agrícola, são autoras e consumidoras de um modo de vida" que precisa ser conhecido, valorizado e explorado nas nossas práticas educativas. É por isso que acreditamos que o rural não apenas não se resume ao agrícola, como também não se encerra ali, nos limites seu do território. Por isso também acreditamos que não é mais possível falar em "fixar o homem no campo", como preconizam algumas políticas mais conservadoras voltadas a essa população, como se as pessoas que ali estão vivessem isoladas do mundo urbano e ignorassem as desigualdades entre a vida no campo e a vida na cidade. Isso fica muito evidente em pesquisas com a juventude (Cf. ALVES, 2013) que mostram que os jovens querem circular nos territórios e têm reclamado serem reconhecidos não apenas como trabalhadores rurais e não apenas dentro do seu próprio território. Eles nos falam de diferentes modos de ser jovem e de diferentes dimensões da condição juvenil no meio rural que extrapolam, e muito, a dimensão do trabalho agrícola. Assim, as pesquisas desenvolvidas pelo grupo poderão nos mostrar outras possibilidades de produção e desenvolvimento local para além do agrícola. É possível identificarmos fontes como o patrimônio natural da região. Entendemos patrimônio na perspectiva de Veiga (2003, p.41):

O patrimônio está longe de se resumir a elementos físicos como a paisagem, obras artísticas ou sítios arqueológicos. Ele também envolve bens imateriais, como as tradições locais, saberes artesanais e culinários ou a própria imagem do território. É o conjunto desses recursos patrimoniais que dá suporte a várias atividades econômicas.

Todas essas questões, que são de natureza multidisciplinar e tem sido historicamente discutidas e estudadas por áreas como a geografia, a agronomia, a sociologia, a história entre outras, desafiam a educação na sociedade brasileira contemporânea e as respostas têm sido dadas por meio de propostas embasadas nos princípios da educação do campo. Trata-se de uma educação pautada nos princípios, valores, necessidades e na diversidade dos povos do campo. Esse termo se contrapõe ao de "educação rural", pautada nos princípios e valores do capitalismo agrário, do agronegócio, na suposta 
incapacidade e inferioridade dos povos do campo e desconsiderando seus anseios, demandas, necessidades e seus saberes (ALVES, OLIVEIRA, 2012).

A disciplina Sociologia e Educação do Campo tem como objetivo geral discutir a relação entre escola e sociedade, problematizando de que modo essas categorias são apresentadas nos clássicos da sociologia e refletindo sobre as contribuições dessas análises para o pensamento educacional brasileiro e para o debate educacional contemporâneo, em especial a proposta educacional da educação do campo. Como objetivos específicos propõem: compreender o papel da sociologia como uma ciência, problematizando a educação e a escola como objetos de análise sociológica; Apresentar e discutir os clássicos da teoria sociológica, enfatizando as contribuições para a sociologia da educação; Discutir as contribuições dos estudos das teorias da Reprodução para a sociologia da educação; Problematizar propostas emergentes de educação popular a partir de debates acerca da defesa da educação pública, da universalização da educação básica e dos direitos dos povos do campo a uma proposta educacional voltada às suas especificidades.

Sendo a habilitação da licenciatura em questão em Ciências da Natureza, a disciplina tem inicio com uma sensibilização dos discentes para o papel dos conhecimentos sociológicos para o trabalho docente, independente da área em que atuará. Isso porque, embora nesta disciplina não trate de uma matéria específica a ser ministrada pelos estudantes do curso, trata dos sujeitos, dos contextos as práticas e das instituições onde a educação acontece. Esse momento inicial constituiu para alguns discentes também momento de familiaridade com a própria disciplina, visto que muitos alunos afirmavam não saber do que tratava a disciplina Sociologia. Algo que experiências prévias tem me mostrado sobre alunos oriundos de classes populares é que os adágios populares funcionam como boas ferramentas de aprendizagem. Nesse sentido uma frase os marcou durante as provocações iniciais sobre a importância dos conhecimentos sociológicos para o trabalho docente foi a seguinte: "Para ensinar latim a Pedro é preciso conhecer latim e conhecer Pedro." Essa frase, cuja autoria desconhecemos, apareceria diversas vezes nas vozes dos discentes ao longo do semestre e nas auto-avaliações 
finais da disciplina, evidenciando que aderiram ao discurso da importância da disciplina para suas condutas profissionais futuras.

Assim, o programa tem início com uma discussão sobre o conceito de imaginação sociológica, de Charles Wright Mills, cujo postulado diz o seguinte:

A imaginação sociológica capacita seu possuidor a compreender o cenário histórico mais amplo, em termos de seu significado para a vida íntima e para a carreira exterior de numerosos indivíduos. Permite-lhe levar em conta como os indivíduos, na agitação de sua experiência diária, adquirem freqüentemente uma consciência falsa de suas posições sociais. Dentro dessa agitação, busca-se a estrutura da sociedade moderna e dentro dessa estrutura são formuladas as psicologias de diferentes homens e mulheres. Através disso, a ansiedade pessoal dos indivíduos é focalizada sobre fatos explícitos e a indiferença do público se transforma em participação nas questões públicas. (MILLS, 1965, p. 11-12).

O conceito foi apresentado aos alunos para instigá-los a pensar sociologicamente não apenas o docente que serão muito em breve, mas a própria estrutura social que relega aos povos do campo condição de subalternidade na nossa sociedade. Quem são e como vivem seus futuros alunos era a questão central à qual eles eram desafiados a pensar do ponto de vista profissional. Ademais, também eram instigados a pensar-se a si próprios, enquanto homens e mulheres do campo ou de origem rural. Eram provocados a refletir sobre o próprio mundo rural, com suas contradições, conflitos e disputas de poder, mas também com suas possibilidades de produção (de riqueza, de saberes, de vida).

Nesse exercício da imaginação sociológica, que é necessário que se diga não foi além de um estágio inicial, muitos se viam confusos à medida que se surpreendiam sendo desafiados a questionar convicções que em alguns casos estavam arraigadas, como a própria questão agrária no nosso país. Quando eram provocados a pensar acerca de termos utilizados pela mídia como "invasão de terra" ou a refletir sobre discursos de que os "movimentos sociais do campo eram baderneiros" se viam diante de dilemas que talvez não se resolverão tão brevemente, mas certamente os provocou a começar a ver a 
questão com outro olhar. Ou seja, as provocações provocavam-lhes inquietações que nem se resolviam nos debates, às vezes até acirravam os ânimos, mas o intento era iniciá-los na trilha dessa busca de possam tornar-se indivíduos capazes "de transitar de um lado a outro da relação entre indivíduo e sociedade e ser capaz de compreender tanto o lugar dos indivíduos como agentes na estrutura social quanto o que essa estrutura faz com os indivíduos" (SOUSA, 2009, p. 13).

O programa seguiu-se com debates acerca de concepções de educação, cultura e sociedade para os clássicos da sociologia, Marx, Weber e Durkheim, e reflexões sobre as instituições socializadoras nas sociedades ocidentais, em especial a escola e a família, sempre estimulando reflexões a partir da realidade concreta dos alunos e preparando-os para o Tempo Comunidade, que no período letivo da disciplina acontecia subseqüentemente ao Tempo Universidade e não concomitantemente, como passou a acontecer a partir do semestre seguinte.

$\mathrm{Na}$ unidade do programa dedicado às teorias da reprodução priorizouse a abordagem cultural desse paradigma e ao enfatizarmos a crítica dos teóricos da reprodução cultural à ideologia do dom os discentes, majoritariamente de origem rural, incorporaram ao debate suas próprias condições de vida. Endossaram a "crítica à ideia de que os indivíduos competiriam dentro de um sistema de ensino em condições iguais, e aqueles que se destacassem por seus dons individuais seriam levados, por uma questão de justiça, a avançar em suas carreiras escolares e, posteriormente, a ocupar as posições superiores na hierarquia social" (NOGUEIRA, NOGUEIRA, 2002). Os discentes traziam ao debate os problemas e dificuldades que enfrentaram para estarem naquele momento dentro de uma universidade e construíam, a partir das suas realidades, críticas contundentes à idéia de um sistema educacional justo e democrático. Nessa construção os conceitos de violência simbólica e de capital cultural ${ }^{3}$ Ihes foram de suma importância, pois logo se deram conta de que, além de sofrerem essa tal violência simbólica,

3 O capital cultural no seu estado incorporado que são as referências culturais, os conhecimentos considerados apropriados e legítimos; no estado objetivado, que são os bens culturais materiais, tais como esculturas, pinturas, livros etc. e o capital cultural institucionalizado que são os títulos escolares. 
uma vez que a escola deslegitima os valores e a cultura dos povos do campo; e que não detinham o capital historicamente valorizado pelo sistema escolar. Esses fatos funcionaram para eles como mecanismos de exclusão do sistema escolar.

As reflexões daí suscitadas azeitam de forma significativa a entrada no debate sobre a demanda por educação pública, que tem Florestan Fernandes como um dos principais expoentes ainda no século passado, e o debate sobre educação popular, bandeira dos movimentos sociais e de representantes da pedagogia crítica, encabeçada no Brasil por Paulo Freire e que vem ganhando forma com propostas educacionais como a educação do campo. O pensamento de Florestan Fernandes foi de suma importância para o debate e desconstrução de algumas posições mais conservadoras que tendem a assumir o discurso criminalizante dos movimentos sociais do campo que a mídia brasileira impõe. Portanto, introduzir o debate a partir de um teórico e não dos movimentos sociais foi estratégico para derrubar alguns argumentos contrários aos movimentos sociais.

Os socialistas não são, como muitos insistem, equivalentes dos dinossauros em busca de nova glaciação. Ao contrário, detêm os meios de análise dos processos que estão em efervescência e, ao mesmo tempo, lutam pelas alternativas que restam à humanidade em virtude da incapacidade do capitalismo de responder positivamente às exigências mínimas do viver coletivo com dignidade (FERNANDES apud SAVIANNI, 1996, p. 82).

Conhecer o pensamento e um pouco da própria história de vida de Florestan Fernandes funcionou como ferramenta importante para os discentes no processo de apreensão das bandeiras que movem os educadores populares e os movimentos sociais. E, assim chega-se à unidade final da disciplina com 0 debate contemporâneo da educação popular e as lutas e conquistas da Educação do Campo. Aqui o diálogo com a pedagogia crítica dá suporte às reflexões, cuja ênfase se pauta na desconstrução da idéia de educação rural e apresentação do paradigma da educação do campo e à proposta de educação libertadora, proposta por Paulo Freire. 


\section{DOS REFERENCIAIS EMPÍRICOS}

Os projetos educacionais dos cursos de educação do campo devem pautar em princípios que respeitem a realidade dos alunos, que dialoguem com sua cultura, seus saberes, seus valores. Acontece que para desenvolver tal proposta faz-se necessário conhecer essa realidade. Nesse sentido, uma das questões discutidas na disciplina foi o contexto educacional brasileiro nas últimas décadas e sobre esse tema os discentes deveriam produzir saberes empíricos, relativos às suas comunidades rurais.

Os sujeitos que colaboraram com esse estudo evidenciaram aspectos relativos infraestrutura das escolas rurais nessa região goiana. As salas eram multisseriadas, funcionavam de forma precária, em locais improvisados, como galpões e até chiqueiros de porcos. O Sr. Divino descreve assim a escola onde estudou: "... as aulas aconteciam na vila, em um rancho coberto de folhas de babaçu e pau a pique e para apoiar os cadernos era uma tábua de madeira em cima de forquilhas. O assento era uma tora bem grande que formava o banco." Ele segue falando sobre o material didático que também era apenas o essencial, como quadro de giz (e muitas vezes faltava giz), alguns poucos livros e a cartilha. Materiais que precisavam levar de casa, fazem questão de frisar.

Nas lembranças do Sr. Divino: "a simplicidade era tanta que tínhamos apenas um lápis, borracha e um caderninho". Essa visão é corroborada pelo relato do Sr. Benedito, de 85 anos: "a escola era muito pequena e toda desarrumada, não tinha coisas básicas, como lousa, giz e apagador e o professor nem sempre vinha dar aula." Portanto, pelos relatos fica evidente que em se tratando de infraestrutura esses sujeitos freqüentaram a escola em condições adversas, precárias, muitas vezes funcionando como um favor, um espaço cedido pelo generoso fazendeiro. Em tais condições os discentes relacionaram a educação nesse contexto com a perspectiva durkheimeana de educação, sobretudo quando identificaram nos seus entrevistados, o que era educação para muitos deles: deve ser passado dos mais velhos para os mais jovens, para as crianças; o que se aprende na escola; o que ensina as regras 
da sociedade foram algumas das respostas. Os discentes também identificaram elementos das teorias da reprodução atuando nas práticas educativas no contexto por eles analisados.

Quando falam da precariedade das escolas e da condição docente os relatos evidenciam quão reprodutora das desigualdades era a educação oferecida naquelas escolas. Alguns dizem que desistiram ainda muito cedo, pois viam que naquela situação não tinham condição de evoluir, de acompanhar os filhos dos ricos, embora tivessem muito interesse pelos estudos, como alegam a maioria dos entrevistados. Sobre isso a D. Chiquita, de Anhanguera", conta que "a escola era uma tarefa difícil. Acho que na minha vida foi a mais estressante. Saía de casa as cinco da manhã para entrar as oito e saía as treze. Quando podia, levava um lanche ou uma fruta, aí eu comia. Do contrário, comer só quando chegar em casa." Vale ressaltar, no entanto, relatos de solidariedade nesse aspecto. Ou seja, alguns dividiam a merenda com os colegas que não tinham.

Além da infraestrutura e da condição docente, outra questão muito aborda foi a didática dos professores, que tinham nos castigos físicos a principal ferramenta de controle dentro da sala de aula. Com apenas uma exceção nos relatos, de uma educadora definida como "fantástica" pelo Sr. Adalberto, os professores são descritos como autoritários, bravos, inflexíveis e violentos, além de serem pessoas "de pouco estudo", nos dizeres do Sr. Manoel, de 82 anos, morador de Pires Belo ${ }^{5}$, que lembra da conivência dos pais no tratamento dispensado pela professora aos alunos: "os pais não se importavam com a maneira como eles tratavam seus filhos. Era necessário aprender, não importando a maneira que repassada essa aprendizagem, se estavam sendo mau tratado, agredidos ou coisa assim. Não tinha problema, era para que aprendessem a lição." Ainda sobre esse aspecto, o Sr. João reafirma que os professores eram autoritários, não conversavam nem aceitavam opinião dos alunos e para isso tinham anuência dos pais "que

\footnotetext{
${ }^{4}$ Menor município do Estado de Goiás com população de 1.020 habitantes (IBGE, 2010), e distante 46,8 Km de Catalão, GO.

${ }^{5}$ Distrito do município de Catalão, GO (com população de 86.647 habitantes (IBGE, 2010)), localiza-se a $36 \mathrm{~km}$ ao norte da sede desse município.
} 
davam liberdade de castigar seus filhos sem reclamar pois acreditavam que aquilo era a verdadeira educação."

Por fim, os discentes foram instigados a dialogar com os moradores das comunidades rurais sobre suas concepções de educação e cultura, dois conceitos discutidos na disciplina. A educação é vista por muitos como redentora, "que tira o indivíduo da ignorância e ajuda a ter uma vida melhor", nos dizeres do Sr. Divino. Essa vida melhor, embora para uns tenha relação com as condições materiais, para outros também tem a ver com as situações de opressão percebidas por eles, pobres e moradores da zona rural, como diz a D. Mariinha, de Anhanguera: "a escola pode ajudar as pessoas a não serem exploradas, a terem uma vida digna", ou seja, embora não se expresse em termos freireanos, a idéia é de que a educação pode libertar, emancipar. Idéia semelhante à de D. Diva, de Goiandira, ${ }^{6}$ que disse não concordar que mulher tem que ser submissa ao marido, e relata que hoje as mulheres estudam, por isso não precisam casar cedo, depender de pai e do marido, como ocorreu com ela, por isso ela é veemente ao dizer que as mulheres precisam estudar ter conhecimento, sabedoria, para serem livres. Assim, também se manifestou a D. Helena, da mesma cidade, que afirma que a vida na roça é ainda mais difícil para as mulheres que precisavam abrir mão dos estudos e aprender os serviços domésticos e a situação piorava se aparecesse um pretendente, pois eram obrigadas a casar, mesmo se ainda fossem adolescentes. Enfim, para além da função redentora, a educação é também vista como emancipadora e como caminho para conquista a admiração e o respeito da sociedade, no entendimento do Sr. Adalberto, de Anhanguera.

Para alguns, educação e cultura são sinônimos, como diz a D. Bela, também de Anhanguera, como define educação como "uma herança cultural que passa de geração a geração." Outros, no entanto, definem cultura em uma perspectiva mais antropológica, não se definindo a partir de um aprendizado escolar, como o Sr. Margarido, morador da Fazenda São Domingos, zona rural de Catalão, para quem "cultura é tudo aquilo que foi repassado pelos nossos pais" e do Sr. João, morador da mesma comunidade, que diz que o trabalho

\footnotetext{
${ }^{6}$ Município do Estado de Goiás com população de 5.265 habitantes (IBGE, 2010), e distante $17,9 \mathrm{Km}$ de Catalão, GO.
} 
pode se tornar um bem cultural, pois com trabalho a pessoa pode viajar e ampliar seus conhecimentos, conhecer as cidades históricas, outras culturas. Ou seja, a cultura é dinâmica, se transforma e nos transforma.

\section{CONSIDERAÇÕES FINAIS}

Quais foram os saberes produzidos por esse grupo de estudantes a partir da atividade proposta na disciplina é o que se tentará responder nas reflexões finais deste trabalho. A que conclusões eles chegaram da relação entre o que foi estudado nos livros e que eles aprenderam com nas suas comunidades, no diálogo com os moradores?

Considerando que a disciplina foi ministrada no segundo período de um curso cujos discentes, em sua maioria, estava há muitos anos longe das salas de aula, concluíram o ensino médio há mais de 15 anos e não tem histórico de pessoas na família com curso universitária, é importante ressaltar a qualidade dos trabalhos produzidos nesse contexto. Conseguiram desenvolver reflexões maduras e bem articuladas às questões teóricas estudadas em sala e, o que no contexto desse curso é um dos propósitos, afirmam ter encontrado mais sentido para o curso e compreendido melhor a necessidade e urgência do curso de educação do campo. Compreenderam na prática o que diferencia o que chamamos hoje de educação do campo, da educação rural a que essas pessoas tiveram acesso.

Ademais, refletiram sobre a importância de se buscar o diálogo com as pessoas mais velhas, de conhecer o mundo que os cerca também a partir do olhar dessas pessoas, e não apenas dos livros. Compreenderam, a partir dos relatos, o contexto que fez com que Florestan Fernandes encabeçasse a luta por educação pública e também que levou os movimentos sociais do campo a lutarem por reforma agrária e por educação e a defesa de Paulo Freire por uma educação libertadora. A história dessas pessoas lhes mostrou porque a educação do campo os movimentos sociais reivindicam não pode ser a mesmas que seus antepassados tiveram. 


\section{REFERENCIAS BIBLIOGRÁFICAS}

ALVES, Maria Zenaide. Ser alguém na vida. Condição juvenil e projetos de vida de jovens moradores de um município rural da região de Governador Valadares/MG. Tese de doutorado. FAE/UFMG. 2013.

ALVES, Maria Zenaide e OLIVEIRA, Igor. A juventude no território: o campo e a cidade. In.: CORREA, Licínia; ALVES, Maria Zenaide e LINHARES, Carla. Cadernos Temáticos: Juventude Brasileira e Ensino Médio. Belo Horizonte: Editora UFMG, 2014.

ARROYO, Miguel. Outros sujeitos. Outras pedagogias. Petrópolis: Vozes, 2012.

CARNEIRO, Maria José. Ruralidade: novas identidades em construção. Estudos Sociedade e Agricultura, v. 11, out. 1998, p. 53-75.

DURKHEIM, Émile. A educação como processo socializador. Função homogeneizadora e função socializadora.

FERREIRA, Ana Paula da Silva de Oliveira. Territórios em conflito: a comunidade Macaúba/Catalão (GO) e a territorialização da atividade mineradora. 2012. 174 f. Dissertação (Mestrado em Geografia) - Universidade Federal de Goiás, Catalão, 2012.

FERNANDES, Florestan. O desafio educacional. São Paulo: Cortez, 1989.

FREIRE, Paulo. Pedagogia do oprimido. Rio de Janeiro: Paz e terra, 1987.

GIDDENS, Anthony. Sociologia. 4. Ed. Lisboa: Fundação Calouste Gulbenkian, 2004.

IANNI, Otávio. A Sociologia de Florestan Fernandes. Revista Brasileira de Ciências Sociais, São Paulo, ano 11, n. 30, fev. 1996, p. 23-28.

MARTINS, José de Sousa. Introdução crítica à sociologia rural. São Paulo: Hucitec, 1981.

MENDONÇA, Marcelo R. A urdidura espacial do capital e do trabalho no Cerrado do Sudeste Goiano. 2004. 457 f. Tese (Doutorado em Geografia) Faculdade de Ciências e Tecnologia, Universidade Estadual Paulista "Júlio de Mesquita Filho", Presidente Prudente, 2004.

NOGUEIRA, Maria Alice; NOUGUEIRA, Cláudio. Bourdieu e a educação. Belo Horizonte: Autêntica, 2009. 
MILLS, Charles Wright. A promessa. In: MILLS, Charles Wright. A imaginação sociológica. Rio de Janeiro: Zahar editores, 1965.

SAVIANE, Demerval. Florestan Fernandes e a educação. Estudos Avançados, 1996.

SOUSA, João Valdir Alves. Introdução à sociologia da educação. Belo Horizonte: Autêntica, 2009.

VEIGA, José Eli da. Cidades Imaginárias: o Brasil é menos urbano do que se calcula. Campinas: Editora Autores Associados, 2003. 